\title{
Vor wor t.
}

Für diesen 38. Jahrgang hat Hr. Professor Dr. F. Neesen litteraturnotizen gesammelt, diese unter die HHrn. Referenten vertheilt sowie an dieselben versendet, und der Unterzeichnete die übrige redactionelle Thätigkeit ausgeführt.

Der $\mathrm{Hr}$. Verleger und der unterzeichnete Redacteur begegneten sich in dem Wunsche, dass jede der beiden ersten Abtheilungen, ähnlich wie die dritte Abtheilung seit dem 36. Jahrgange, einen besondern Band bilde. Um aber die grössere Zusammengehörigkeit der beiden ersten Abtheilungen gegenüber der dritten Abtheilung hervorzuheben, wird für jene ein gemeinsames Register am Schluss der zweiten Abtheilung gegeben werden. Aehnlich kurze Titel, wie Physik der Erde für die dritte Abtheilung, wurden dadurch erhalten, dass die Mousson'sche Bezeichnung verwendet wurde: Physik der Materie für die erste Abtheilung (Allgemeine Physik, Akustik), Physik des Aethers für die zweite Abtheilung (Optik, Wärmelehre, Elektricitätslehre).

Vom Jahre 1883 ab hat der jetzige Redacteur gleich beim Sammeln von Litteraturnotizen berücksichtigt, ob ein Citat sich auf eine Originalabhandlung bez. deren Uebersetzung, oder ob es sich nur auf einen Auszug bez. ein Referat der Abhandlung bezieht; denn er erstrebt das Ziel, dass einerseits die Referate in den Fortschritten der Physik nach den Originalabhandlungen gegeben werden, nur, falls eine Abhandlung weder für ihn noch den 
Hrn. Referenten erreichbar ist, ausnahmsweise nach Referaten kurze Bemerkungen über den Inhalt derselben gemacht werden, und anderseits möglichst vollständig mitgetheilt wird, wo Uebersetzungen, grössere Auszüge und wichtigere Referate über eine Abhandlung veröffentlicht sind. Die Erreichung dieses Zieles kann wesentlich erleichtert und beschleunigt werden, wenn die HHrn. Verfasser physikalischer Abhandlungen allgemeiner, als bisher, die Güte haben würden, Separatabzüge von ihren Publicationen (von welchen die seit Anfang des Jahres 1884 erschienenen noch verwerthet werden können) an die Redaction zu schicken, und wenn diejenigen Herren, unter deren Leitung Arbeiten von physikalischem Interesse ausgeführt werden, der vorliegenden Publication die Gunst würden erweisen wollen, dass sie zu solchen Einsendungen anregten. So weit ohne zu grossen Zeitaufwand bei der Vorbereitung des Manuscripts für den Druck festgestellt werden konnte, ob sich ein Citat auf ein Referat bezog, ist dies bereits in diesem Jahrgange kenntlich gemacht.

\section{E. Rosochatius.}

